TITLE:

\title{
Forensic analysis of arsenic poisoning in Japan by synchrotron radiation $\mathrm{X}$-ray fluorescence
}

$\operatorname{AUTHOR}(\mathrm{S}):$

Kawai, Jun

\section{CITATION:}

Kawai, Jun. Forensic analysis of arsenic poisoning in Japan by

synchrotron radiation X-ray fluorescence. X-Ray Spectrometry 2013, 43(1): 2-12

\section{ISSUE DATE:}

2013-05-30

URL:

http://hdl.handle.net/2433/197745

\section{RIGHT:}

This is the peer reviewed version of the following article: Kawai, J. (2014), Forensic analysis of arsenic poisoning in Japan by synchrotron radiation X-ray fluorescence. X-Ray Spectrom., 43: 2-12, which has been published in final form at http://dx.doi.org/10.1002/xrs.2462; この論文は出版社版でありません。引用の際には出版社版をご確認じ利用くださ $\iota_{\circ} ;$ This is not the published version. Please cite only the published version. 
Submitted to X-Ray Spectrometry, Forensic Special Issue, August 10, 2012

Revised on October 5, 2012

Revised on February 16, 2013

Journal "X-Ray Spectrometry” http://onlinelibrary.wiley.com/doi/10.1002/xrs.2462/abstract

PDF download is now free at http://onlinelibrary.wiley.com/doi/10.1002/xrs.2462/epdf

Review

Forensic Analysis of Arsenic Poisoning in J apan by Synchrotron Radiation X-ray Fluorescence

Jun Kawai

Department of Materials Science and Engineering, Kyoto University, Sakyo-ku, Kyoto 606-8501, Japan

Abstract: Synchrotron radiation X-ray fluorescence (SR-XRF) analysis reports of a poisoning case by arsenic, July 25, 1998, J apan, for forensic investigation purposes are reviewed. In these forensic analyses, SPring- 8 and KEK-PF beamlines were used for minor element ( $\mathrm{Sn}, \mathrm{Sb}, \mathrm{Mo}, \mathrm{Bi}, \mathrm{Ba}$ ) analysis in the arsenic pesticide specimens, sampled at the crime scene as well as the neighborhood of the suspect. For this case, two kinds of documents were submitted to court; one was a qualitative analysis and said to be a "pattern recognition" by Prof. Nakai. The other was, by Profs. Taniguchi and Hayakawa, a quantitative analysis after background subtraction, normalized by the sample thickness, where calibration curves were made with reference to the ICP-AES analysis for reference samples. The final decision of the court was a death sentence based on the qualitative "pattern recognition". The present review concludes that the quantitative analysis by Profs. Taniguchi and Hayakawa was scientifically more important than the "pattern recognition" qualitative analysis, because the Taniguchi-Hayakawa report used novel but reliable data processing methods. The $\mathrm{Sn}, \mathrm{Sb}$ and Mo Ka intensities were normalized with respect to the As (major element) $\mathrm{K} \alpha(10.5 \mathrm{keV})$ intensity as a thick target, while the $\mathrm{Bi}$ and $\mathrm{Ba} \mathrm{K} \alpha$ intensities were normalized by the Rayleigh scattering (for $116 \mathrm{keV}$ incident beam) as a thin target. The Taniguchi-Hayakawa report was the first quantitative report in high energy SR-XRF analysis. The most important conclusion in the present review is that the ICP-AES was more reliable over these SR-XRF analyses, because even the beamline selection was not possible without the knowledge of the impurity elements obtained by the ICP-AES. Five elements (Se, Sn, $\mathrm{Sb}, \mathrm{Pb}$, and $\mathrm{Bi}$ ) were able to be used in ICP-AES for identification compared to only three 
elements ( $\mathrm{Sn}, \mathrm{Sb}$, and $\mathrm{Bi}$ ) in SR-XRF. High blank intensity resulted from using $\mathrm{Pb}$ for X-ray collimator in the beamline. Overlapping of the analytical lines of minor Se and major As prevented the use of Se for identification. Recent analysis of Fe, Zn, Mo, and Ba in the Nakai's raw spectra measured in 1998 reveals the arsenic stored in the kitchen of the condemned criminal in the death row was significantly different from that of the paper cup used for poisoning.

Keywords: SR-XRF, As, Impurity, Thick and thin target

1. Introduction

Four people were killed and 63 others became sick as curry poisoned by arsenic was served during a summer festival in Wakayama City, Japan, on July $25^{\text {th }}, 1998$ [1]. An insurance saleswoman was arrested for murder and attempted murder, and after long trials from a district court to the supreme court, the saleswoman was sentenced to death without confession, based on a key evidence of the synchrotron radiation X-ray fluorescence (SR-XRF) analysis. The purpose of the present review is to summarize the SR-XRF analysis documents submitted to the court from experts of X-ray fluorescence analysis. The analytical chemistry experts prepared more than 30 documents including laboratory XRF and SR-XRF. The chemical analysis methods used in these documents were ICP-AES, ion chromatography, IR, XRD, SEM-EDX, ED-XRF, WD-XRF, SR-XRF, SR- $\mu$ XRF, transmission X-ray imaging, and of course, wet chemical analysis methods such as the Gutzeit test [2] to detect arsenic. The abbreviations used in the present review are listed in Table 1. Details of the instruments used in the X-ray spectroscopic methods are listed in Table 2.

IR, XRD, SEM-EDX, Gutzeit test, and laboratory XRF concluded the presence of arsenic. At an early stage of the case, it was believed that curry was served with rotten ingredients in it. Then cyanide was erroneously detected. The detection of arsenic was a key analysis for the medical treatment of the victims, but too late. On the other hand, $\mathrm{SR}-\mathrm{XRF}$ and ICP-AES concluded the presence of minor impurity elements ( $\mathrm{Sn}, \mathrm{Sb}, \mathrm{Bi}$, Mo for SR-XRF and Sn, Sb, Bi, Se, Pb for ICP-AES) and were used for the identification of the specimens found in the curry, in a paper cup found at the curry pot, at the suspected saleswoman's house, and her neighborhood houses. It was clear that the criminal brought the arsenic in the paper cup to the curry pot. Therefore the identification of arsenic remained in the paper cup, in the curry pot, and that stored in several houses in this area was a key evidence to find the criminal. Arsenic was used for pesticide of white ants, and eradicators of termites were not an unusual job in this area. 
Table 1. Abbreviations

\begin{tabular}{|l|l|}
\hline ICP-AES & Inductively coupled plasma atomic emission spectrometry \\
\hline IR & Infrared \\
\hline XRD & X-ray diffraction \\
\hline SEM-EDX & $\begin{array}{l}\text { Scanning electron microscope, energy dispersive X-ray } \\
\text { spectrometry (or analysis) }\end{array}$ \\
\hline SSD & Solid state detector \\
\hline XRF & X-ray fluorescence \\
\hline ED-XRF & Energy dispersive X-ray fluorescence \\
\hline WD-XRF & Wavelength dispersive X-ray fluorescence \\
\hline WD-SR-XRF & Wavelength dispersive synchrotron radiation X-ray fluorescence \\
\hline EDX, EDS & Energy dispersive X-ray spectrometry \\
\hline WDX, WDS & Wavelength dispersive X-ray spectrometry \\
\hline SR-XRF & Synchrotron radiation X-ray fluorescence \\
\hline SR- $\mu$ XRF & Synchrotron radiation micro(beam) X-ray fluorescence \\
\hline KEK-PF & High Energy Research Organization, Photon Factory \\
\hline SPring-8 & $\begin{array}{l}\text { Super } \text { Photon ring-8 GeV, owned and managed by RIKEN, and } \\
\text { the J apan Synchrotron Radiation Research Institute (J ASRI) is } \\
\text { commissioned by RIKEN. }\end{array}$ \\
\hline
\end{tabular}

Table 2. X-ray spectroscopic instruments used in the legal advices

\begin{tabular}{l|l}
\hline SEM-EDX & $\begin{array}{l}\text { JEOL JSM-5410LV } \\
\text { Cameca SX-100 with PGT EDX detector } \\
\text { Akashi ABT-55WETSEM with EDAX-9800 detector }\end{array}$ \\
\hline ED-XRF & SII SEA5120 \\
\hline WD-XRF & Philips 1404 \\
\hline SR-XRF & $\begin{array}{l}\text { SPring-8 BL-08W high energy wiggler beamline with Ge SSD } \\
\text { SPring-8 BL-39XU undulator beamline with LiF(200) WD-XRF } \\
\text { KEK-PF BL-4A bending magnet beamline with Si(Li) and Ge SSD }\end{array}$ \\
\hline SR- $\mu$ XRF & SPring-8 BL-08W, BL-39XU, and KEK-PF BL-4A \\
\hline
\end{tabular}


Table 3. Legal advice document numbers, date of submission, and name of authors.

\begin{tabular}{l|llll}
\hline Document \# & method & Submitted date & Author(s) & Ref. \\
\hline$\# 1168$ & ICP-AES & December 15th, 1998 & Dr. Marumo et al. & 7 \\
$\# 1170$ & SR-XRF & February 19th, 1999 & Prof. Nakai & 3 \\
$\# 6$ & SR-XRF & November 5th, 2001 & Profs. Taniguchi and Hayakawa & 4 \\
$\# 7$ & SR-XRF & November 15th, 2001 & Prof. Hayakawa's addenda to \#6 & 5 \\
$\# 8$ & SR-XRF & November 22nd, 2001 & Prof. Hayakawa's revision of \#6 & 6 \\
\hline
\end{tabular}

The main documents related to the SR-XRF are \#1170 prepared by Prof. Nakai [3], \#6 by Profs. Taniguchi and Hayakawa [4], \#7 (Hayakawa's addenda [5]), and \#8 (Hayakawa's revision [6]). The SR-XRF analysis \#1170 has been performed by the request of the procecutor, while the analysis of \#6 by the order of the court. The present review focuses on these documents, \#1170, and \#6-\#8, with a comparison to ICP-AES in the document \#1168 reported by Dr. Marumo et al. [7], where Marumo et al. performed quantitative analysis of $\mathrm{Se}, \mathrm{Sn}, \mathrm{Sb}, \mathrm{Bi}$ and $\mathrm{Pb}$ as impurity elements in the collected pesticide specimens. The document numbers and date of submission to the court are summarized in Table 3.

It is a concise summary to start with the reply of the public prosecutor, Ms. A. Fukuda, to the request of the chemical analysis by the retrial lawyers group of the condemned criminal in the death row [8]. The reason, Prosecutor Fukuda has denied the request of the chemical analysis was, she stated, "The chemical analysis method Prof. Nakai used was only reading the strong/weak relations of the characteristic X-ray lines in the raw SR-XRF spectra, without deducing the concentration of the indexed elements. This is because if Nakai converts the spectra of the indexed elements into their concentrations, he needs various kinds of data corrections, and during these numerical processings, due to the effects of individual specimen characteristics as well as unavoidable errors, the concluded concentration values will be unreliable." This statement is quite strange from the analytical chemist point of view, because the XRF spectral peak intensity is not always proportional to the concentration, but a complicated function of its matrix. The raw peak intensity itself is not directly related to its concentration and thus we, analytical experts, convert the peak intensity into the concentration of each element, after the correction of the matrix effects, such as the absorption effect, enhancement effect, and thickness of the specimen. The background subtraction is an important step before data analysis, though Fukuda's reply neglects the importance of the background subtraction.

Prosecutor Fukuda stated in the same document, "On the contrary, 
Taniguchi-Hayakawa analysis was for the same arsenic crystal specimen that Nakai analyzed, however, only a very narrow area in the crystal was irradiated by the SPring-8 synchrotron radiation X-ray beam, and based only on this analysis, they concluded a possibility of identity to other arsenic specimens collected. Taniguchi-Hayakawa's conclusion is based on the assumption that the specimen crystal found in the curry was recrystallized, after it has once been dissolved (into curry)." It is also interesting to point out that Prosecutor Fukuda states, "The fact that arsenic sum peaks found in the Nakai's spectra means the sample amount was enough for synchrotron radiation analysis." She continues, "Taniguchi-Hayakawa's spectra show no sum peaks, which means the beam size was too small”. The beam size Nakai used in \#1170 was $2 \mathrm{~mm} \times 2 \mathrm{~mm}$, while Hayakawa used $0.3 \mathrm{~mm}$ ordinate and $0.5 \mathrm{~mm}$ abscissa, i.e. $1 / 27$ or $1 / 28$ beam area of that used by Nakai, described at p.16 of Prof. Hayakawa's testimony dated on December $3^{\text {rd }}$, 2001. Prosecutor Fukuda refers to Hayakawa's testimony in her reply: Hayakawa says, "There is no contradiction that these specimens (corrected from the suspect and her neighborhood houses and sampled from the curry) are identical arsenic. But because of the lack of information how much arsenic of the same lot is in the market, we cannot conclude they are originated from the saleswomen; we only conclude they are originated from the same lot." All the reasons Prosecutor Fukuda described in her document have already been described in the judicial decision document which has been prepared by the Judge and as thick as 982 pages.

It is very strange that too strong or wide $(2 \mathrm{~mm} \times 2 \mathrm{~mm})$ incident X-ray beam was concluded to be superior to the micro-beam $(0.3 \mathrm{~mm} \times 0.5 \mathrm{~mm})$, because of the presence of the "sum peaks". Here the sum peak means As $K \alpha+K \alpha, K \alpha+K \beta$, and $K \beta+K \beta$ in the spectra, because the synchrotron was too strong to avoid the pile up of the $X$-rays from the major element, As, when the SSD amplifier constants were selected carelessly. As a general rule, if we avoid the pile up effect by rapid analogue/digital converting, the energy resolution becomes worse. When strong sum peaks appear, the detector is partially saturated and thus the counting linearity as well as the energy resolution are worse than that measured without the sum peaks. It is also interesting to point out that Fukuda thought that the beam size of Taniguchi-Hayakawa experiment was too small (one twenty-eighth), and the obtained spectra do not represent the whole specimen on the sample stage. However, Hayakawa measured 5 points on Specimen 4, a representative specimen, in order to estimate the inhomogeneity of the specimen, using the $0.3 \mathrm{~mm} \mathrm{x}$ $0.5 \mathrm{~mm}$ SR X-ray beam. He estimated the standard deviation as the change of the position on the specimen surface, resulted that the deviation was negligible. After 
these validations of the SR-XRF analysis, Hayakawa also deduced the quantitative concentrations after the thick or thin sample correction, and compared the obtained concentration value with those obtained by ICP-AES. When the characteristic X-ray energy is high but the sample thickness is thin, the XRF intensity increases as a function of the thickness of the sample (so-called "thin sample"); while the characteristic X-ray energy is low, the XRF intensity does not change when the thickness of the sample changes ("thick sample"). However, at the final decision made by the judge, Hayakawa's numerical processings are treated as a source of error, and how the spectra look similar decided by Prof. Nakai, which was called as a "pattern recognition" by Nakai himself, without subtraction of the background, without the thick/thin target corrections, and without deducing the elemental concentrations, is a key evidence for the death sentence. The term "pattern recognition" which Nakai used at the court, then officially used in the court, was completely different from that used in informatics.

The conclusions of the present review are summarized as follows.

(1) Before the SR-XRF analysis by Prof. Nakai, five elemental concentrations have already been obtained by ICP-AES by Dr. Marumo et al. From the "radar chart" of Dr. Marumo, the identity has already been clarified among the specimens collected from the local district. Here a typical "radar chart" is shown in Fig. 12 below. The concentrations of the impurity elements were more than of the order of a few tens of ppm, and thus a trace elemental analysis by using the $3^{\text {rd }}$ generation synchrotron radiation facility such as SPring-8 was not necessary; now it is possible even by a handheld XRF spectrometer, if the sample amount is enough. The amount of the sample in the paper cup was $29.1 \mathrm{mg}$ arsenic powder. It was true that the sample found in the saleswoman's house was said to be $0.1 \mathrm{mg}$, and for this analysis the SR-XRF might be needed. However a mass spectrometer was also applicable, but not tried. Without knowledge of the impurity elements ( $\mathrm{Se}, \mathrm{Sn}, \mathrm{Sb}, \mathrm{Pb}, \mathrm{Bi}$ ), Prof. Nakai could not even select the beamline of a synchrotron facility. For SR-XRF, Pb and Se could not be used for the identification, because $\mathrm{Pb}$ was used for the beam collimator; minor Se $\mathrm{K} \alpha(11.2 \mathrm{keV})$ was overlapped by major $\mathrm{As} \mathrm{K} \beta(11.7 \mathrm{keV})$.

(2) The most important element for identification was Mo for the murder. However Mo is not possible to be effectively excited by $115 \mathrm{keV}$ incident X-ray beam (BL-08W at SPring-8) because of its too low ionization cross-section and thus KEK-PF (20-21 $\mathrm{keV}$ incident beam) was again used. However, because of the strong interference from the As sum peak $(21 \mathrm{keV})$, Mo K $\beta$ (19.6 keV) has not been observed, and only one single peak Mo K $\alpha(17.4 \mathrm{keV})$ has been used to prove the presence of Mo, which was on the strong low energy tail of the As sum peak. Only one single peak of Mo 
on the intense low energy tail of the SSD spectra is not a strong evidence for the death penalty.

(3) Taniguchi-Hayakawa analysis has the following characteristics: (i) They measured 5 spatial points of Specimen 4 in order to know the reproducibility as well as the homogeneity of the specimen using the $0.3 \mathrm{~mm} \times 0.5 \mathrm{~mm}$ SR beam. (ii) The background subtraction method they initially used was a smooth curve passing through 30 points on a spectrum. However this curve overestimated the background intensity when a weak peak's background was subtracted. Then Prof. Hayakawa used a linear background for each peak. The starting and end points of the linear background were fixed at the same energies for the same elements throughout the analysis. (iii) Prof. Hayakawa also calculated the concentration of the key elements after the correction of the probing depth depending on the X-ray fluorescence energy, i.e., the thickness of the specimen. That is to say, the characteristic X-ray intensities were normalized with respect to the As Ka intensity (for $\mathrm{Sn}, \mathrm{Sb}$, and $\mathrm{Mo} \mathrm{K} \alpha$ ) or Rayleigh scattering intensity at $116 \mathrm{keV}$ incident SR beam (for $\mathrm{Bi}$, and $\mathrm{Ba} \mathrm{K} \alpha$ ) depending on the effective specimen thickness. The documents submitted to the court by Prof. Hayakawa was the first report of the high energy ( 100 keV) XRF quantitative analysis, using the As K $\alpha$ normalization (thick sample) or Rayleigh scattering normalization (thin sample), though no academic paper has been published so far by Hayakawa.

(4) It was believed that Nakai proved that the saleswoman's arsenic was identical to the arsenic in the paper cup, which was found near the curry pot. It has been opened by Nakai in an annual Japanese X-ray Analysis Discussion Meeting on November $2^{\text {nd }}, 2013$, that all the arsenic collected from the neighborhood, the saleswoman's house, curry pot, and the paper cup were identical, judged from the "pattern recognition" of $\mathrm{Sn}, \mathrm{Sb}, \mathrm{Bi}$, and Mo. Nakai did not prove that the saleswoman's arsenic was exclusively identical to the paper cup arsenic.

(5) Kawai analyzed Fe, Zn, Mo, Ba, As X-ray intensity in the spectra measured by Nakai, and concluded that a significant difference exists between the arsenic of saleswoman's house and that of paper cup.

2. Document \#1170 submitted by Prof. Nakai

Prof. Nakai used SPring-8 BL-08W wiggler beamline for the beamtimes of December $11^{\text {th- }} 13^{\text {th }}$ and $18^{\text {th- }} 19^{\text {th }}, 1998$. He used $115 \mathrm{keV}$ incident X-ray beam with the size of $2 \mathrm{~mm} \times 2 \mathrm{~mm}$. One spectrum was measured for 2400 seconds (40 minutes). $\mathrm{X}$-ray detector was Ge SSD. He also used KEK-PF BL-4A bending magnet beamline 
where 20-21 keV incident beam with $2 \mathrm{~mm}$ x $2 \mathrm{~mm}$ beam size was used, from December $14^{\text {th }}$ to $16^{\text {th }}$, 1998; dwelling time of 2400 seconds was again used for one spectrum.

Figure 1 shows two examples of his measured spectra at SPring-8. Arsenic $\mathrm{K} \alpha$ and $\mathrm{K} \beta$ are found at around $11 \mathrm{keV}$, and probably Compton scattering of $115 \mathrm{keV}$ incident X-rays is found at $95 \mathrm{keV}$. Mo, Sn, Sb, and Bi peaks are found in the enlarged spectra, but many other non-assigned peaks such as $\mathrm{Pb} \mathrm{K \alpha _{1 }}(75.0 \mathrm{keV}), \mathrm{K} \alpha_{2}(72.8 \mathrm{keV})$, and $\mathrm{K} \beta_{1}(84.9 \mathrm{keV})$ are found. The asymmetric wide peaks at around $21 \mathrm{keV}$ are the As sum peaks (As $K \alpha \times 2$, As $K \alpha+K \beta$, and $A s K \beta \times 2$ ).

Prof. Nakai also measured the distribution of As in a hair with the beam size of $1 \mathrm{~mm} \times 3 \mathrm{~mm}$ at KEK-PF BL-4A. The incident energy was 12.2 or $12.9 \mathrm{keV}$ (As K absorption edge was $11.9 \mathrm{keV})$. He measured As $\mathrm{K} \alpha$ by every $1 \mathrm{~mm}$ step with 50 seconds, using a $\mathrm{Si}(\mathrm{Li}) \mathrm{SSD}$. This analysis is not treated in the present review.

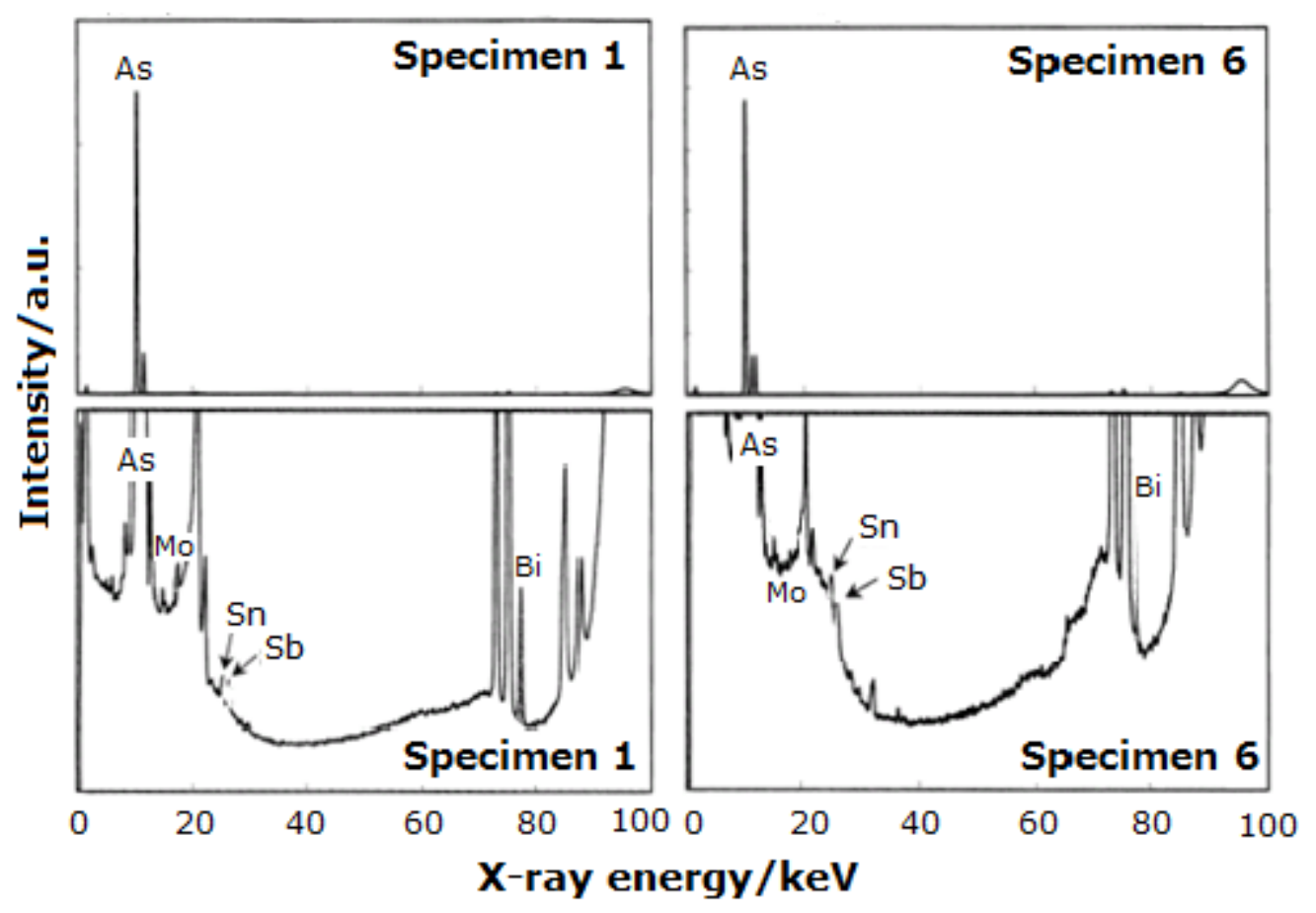

Fig. 1 X-ray spectra measured by Prof. Nakai at SPring-8 BL-08W for Specimens 1 and 6 (taken from Document \#1170).

It should be noted in Fig. 1 that (i) the Compton scattering intensity (at $95 \mathrm{keV}$ ) changes between Specimens 1 and 6, (ii) the top two spectra seem to be plotted normalized with respect to the peak height of the As $\mathrm{K} \alpha$, but this is not described in the document, (iii) the asymmetry of the As sum peaks changes, (iv) the intensity is 
displayed by arbitrary units and thus we cannot know the true counting rates, i.e. true counting statistics. If the intensities are 100 and 1000,000 counts per seconds for these two specimens, they are not identical even though the spectral shapes are similar, if the irradiated volume of the specimen is the same. (v) The incident elastic scattering peak at $115 \mathrm{keV}$ is outside the plot range, and not recorded.

Fig. 2 shows two spectra for one single particle found from the curry, but the positions irradiated were different on the same particle. It is found from Fig. 2 that the Compton intensity is different, which means either the effective volume was different, effective atomic number was different, or the incident beam intensity fluctuated. At an early stage of just after the SPring- 8 was in use, the incident beam was not stable and sometimes the beam was escaped from the sample, due to a heat load of the monochromator crystals. I have experienced that the beam position was moved by a few $\mathrm{cm}$ on the sample in an early stage of the SPring-8, almost at the same year when the present arsenic analysis was performed.

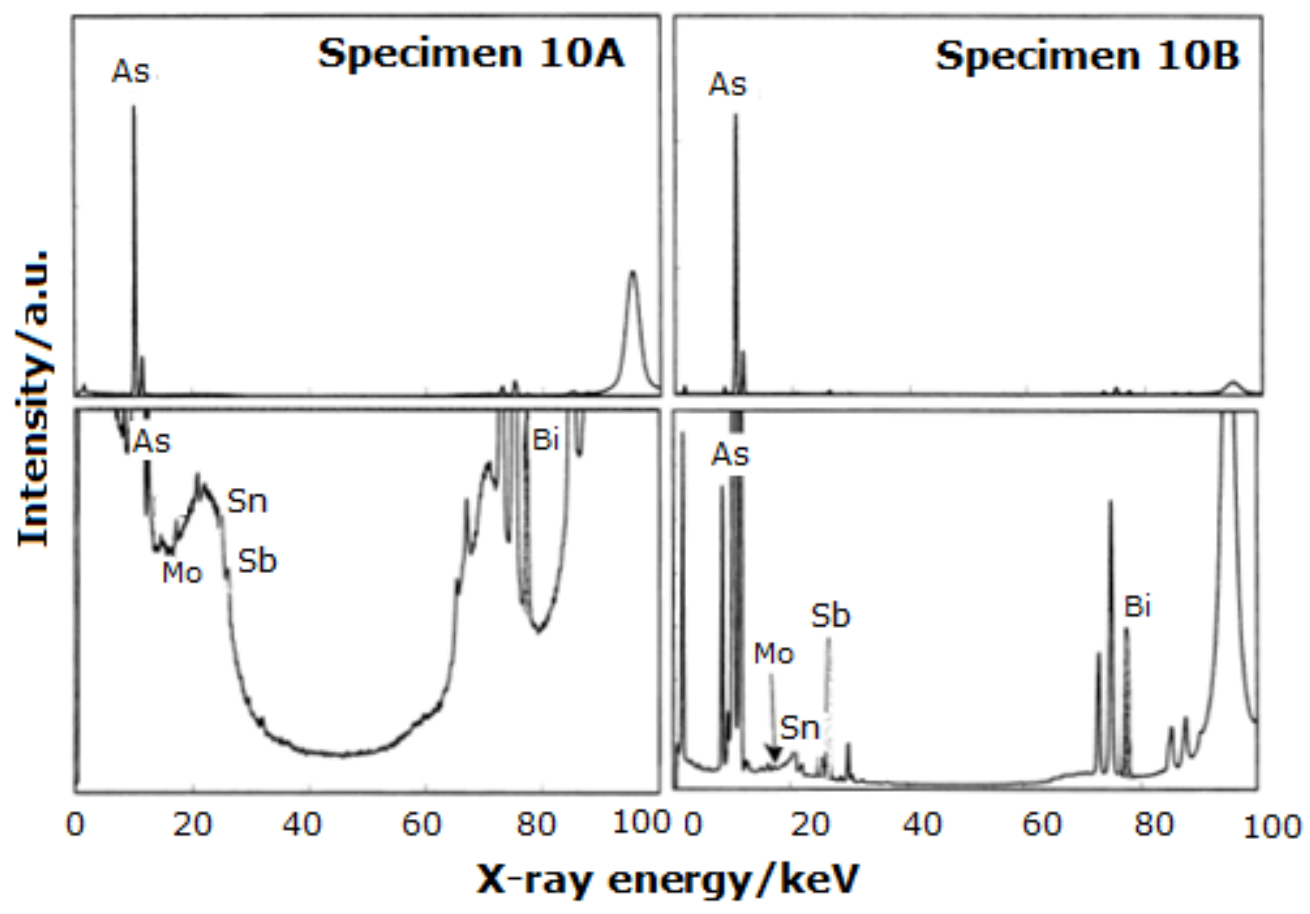

Fig. 2 Spectra of a crystal particle (Specimen 10) found in the curry. Two places (A and B) of the same particle were measured (from \#1170).

Fig. 3 shows representative Mo spectra measured by Prof. Nakai at BL-4A beamline of the Photon Factory (PF), KEK. A "paper cup" was found in the trash near the curry pot, and the murder used the "paper cup" to bring the arsenic. The arsenic 
powder of $29.1 \mathrm{mg}$ was left in the cup. The density of arsenic is relatively high and thus the weight we guess from its volume is heavier than is expected. Most of the 29.1 mg was consumed for ICP-AES analysis by Dr. Marumo. However, when the paper cup was irradiated by SR beam at KEK-PF, Nakai wrote in his document that the X-rays from As was too strong, and thus large amount of arsenic existed on the whole surface of the paper cup, that the X-ray detector was saturated and the measurement was almost impossible. Because the signal to noise ratio of the "paper cup" spectrum is better than that of Specimen 4, as is found from Fig. 3; the residue was enough for the SR-XRF analysis. Specimen 8 in Fig. 3 does not show any Mo peak. Specimen 8 was not related to the murder case, and thus Mo is characteristic for the specimens related to the murder incidence. We must note here that the absence of Mo K $\beta(19.6 \mathrm{keV})$ peak in Specimen 4 of Fig. 3 is strange; $\mathrm{K} \beta$ is out of the plot range for the "paper cup" spectrum in Fig. 3. Usually we, analytical chemists, do not conclude presence of an element by one single peak of X-ray fluorescence alone. Background increase at $20 \mathrm{keV}$ was due to the strong As sum peak tailing, and also due to the incident beam elastic scattering. This means that the use of EDX is not appropriate for the minor element Mo analysis in major As matrix, or an additional Mo L $\alpha$ peak has to be used. Hayakawa measured WD-SR-XRF spectra at SPring-8 BL-39XU, which exhibited Mo $K \alpha_{1}$ and $K \alpha_{2}$ with 2:1 intensity ratio, and thus until 2001 (see Table 2), the existence of Mo was not proved in the case. Some other document reported the ED-XRF analysis using SII SAE5120, showing the Mo L $\alpha$ peak $(2.3 \mathrm{keV}$ ) without description of the X-ray tube; SAE5120 usually uses Mo target X-ray tube.

In the testimony by Nakai in the $43^{\text {rd }}$ public trial record (p.129), one of the defense lawyers group asked, "You find the peaks in the spectra, you have seen them by eyes, and then you have concluded that bismuth and tin are about the same. Have you deduced the numerical values? Or have you calculated the integrated intensity?" Nakai replied, "No, I haven't calculated." Then lawyer asked, "In short, you see the graphs by eyes," and Nakai continues, "It is the pattern recognition."

The effective sample thickness is thin for Bi but thick for Sb, according to analysis of Hayakawa below. Thus the spectral intensity should be normalized with respect to the As $\mathrm{K} \alpha$ or Rayleigh peak intensities as is discussed in the next section before calculating the ratio. It should be pointed out that Nakai's analysis lacks the concept whether the sample is thick or thin for X-rays detected. 


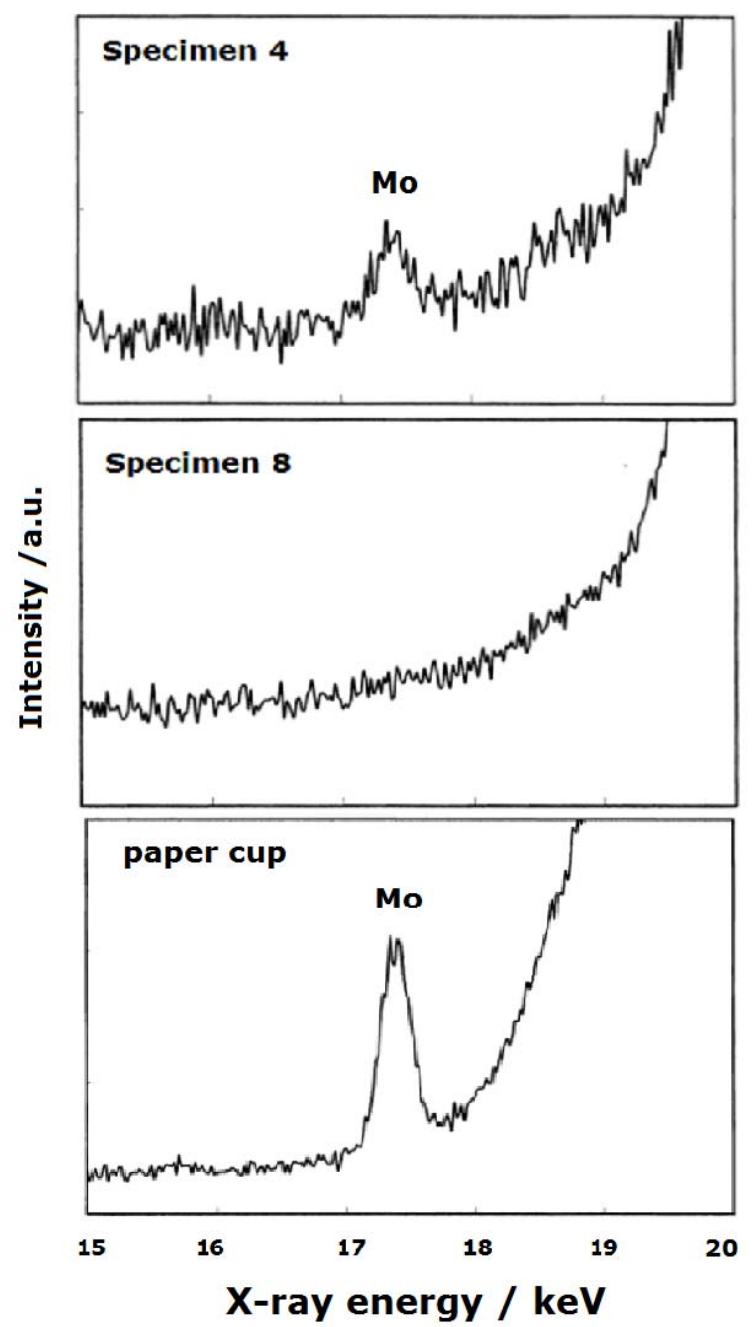

Fig. 3 Mo K $\alpha$ spectra measured at KEK-PF BL-4A, taken from \#1170.

3. Documents \#6, \#7, and \#8 by Profs. Taniguchi and Hayakawa

The team of defense lawyers requested the court the same synchrotron radiation analysis as Prof. Nakai did in December 1999. Based on this request, Wakayama district court ordered Profs. Taniguchi and Hayakawa to analyze again, dated on July $13^{\text {th }}$, 2001. The analyses presented in Taniguchi-Hayakawa's documents were more precise and quantitative compared with that of Nakai. Taniguchi-Hayakawa's data are presented with "reliability index" which they call, and thus much more quantitatively accurate than the "pattern recognition" used by Nakai. The "reliability index" is defined as the ratio of the integral peak intensity (after the linear background has been subtracted) divided by the background intensity. This is similar to the expression of the detection limit. Profs. Taniguchi and Hayakawa were ordered to conclude the following 3 points by Judge: 
(i) Identify the Specimens 1-9. (Here we must note that the specimen numbers used by Taniguchi-Hayakawa's documents do not correspond to those used by Nakai, also do not correspond to those used by Marumo).

(ii) Clarify the meaning of $\mathrm{Mo}, \mathrm{Sn}, \mathrm{Sb}$, and $\mathrm{Bi}$.

(iii) Clarify the meaning of the existence of Ba.

The Document \#6 was finished on November $5^{\text {th }}, 2001$, but after the document was checked by Judge, he asked Taniguchi and Hayakawa to conclude whether Specimens 6-9 are the same kind of Specimens 1-5 or not. Judge may have wanted to know whether Mo was contained in the specimens related to the murder, and whether Mo was not contained in the specimens not related to the murder. This is because the spectra shown in Fig. 3 were too weak evidences as is discussed above. Accordingly, Document \#7 (addendum) was submitted as the response to Judge's request, dated on November 15th 2001 . During preparing Document \#7, Hayakawa found that the background subtraction method used in Document \#6 was inappropriate. As is described in the introduction, they initially used a smooth curve as a background passing through 30 points on a spectrum. However Prof. Hayakawa checked the peak intensity by enlarging each elemental peaks, in order to reply to the request of Judge, Hayakawa found several peak intensities were under-estimated. In order to improve this situation, Hayakawa recalculated the spectral intensity by subtracting the linear background as shown in Fig. 4.

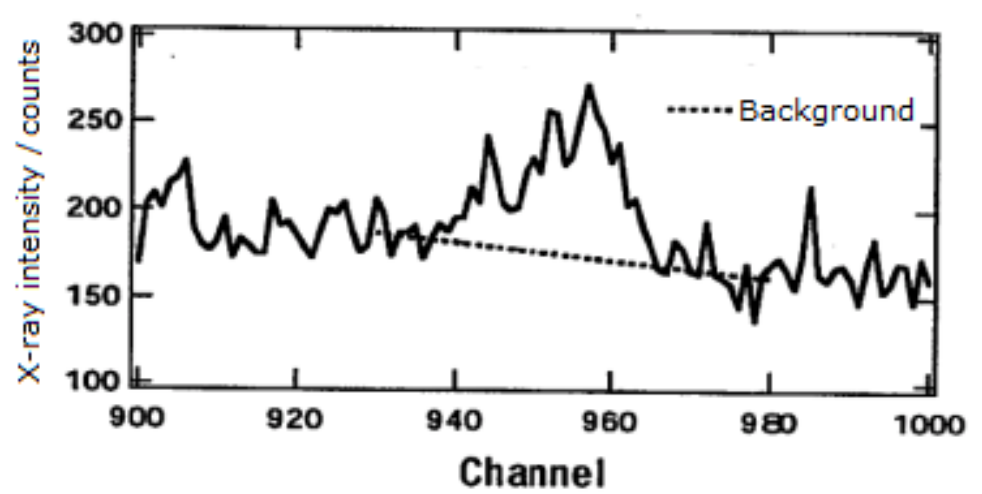

Fig. 4 A linear background used by Prof. Hayakawa in Documents \#7 and \#8. The starting and end points were fixed for an element throughout all the spectra analyzed. The average of 5 points for each side of the peak was used for the starting and end points of the linear background. 


\section{Experimental station}

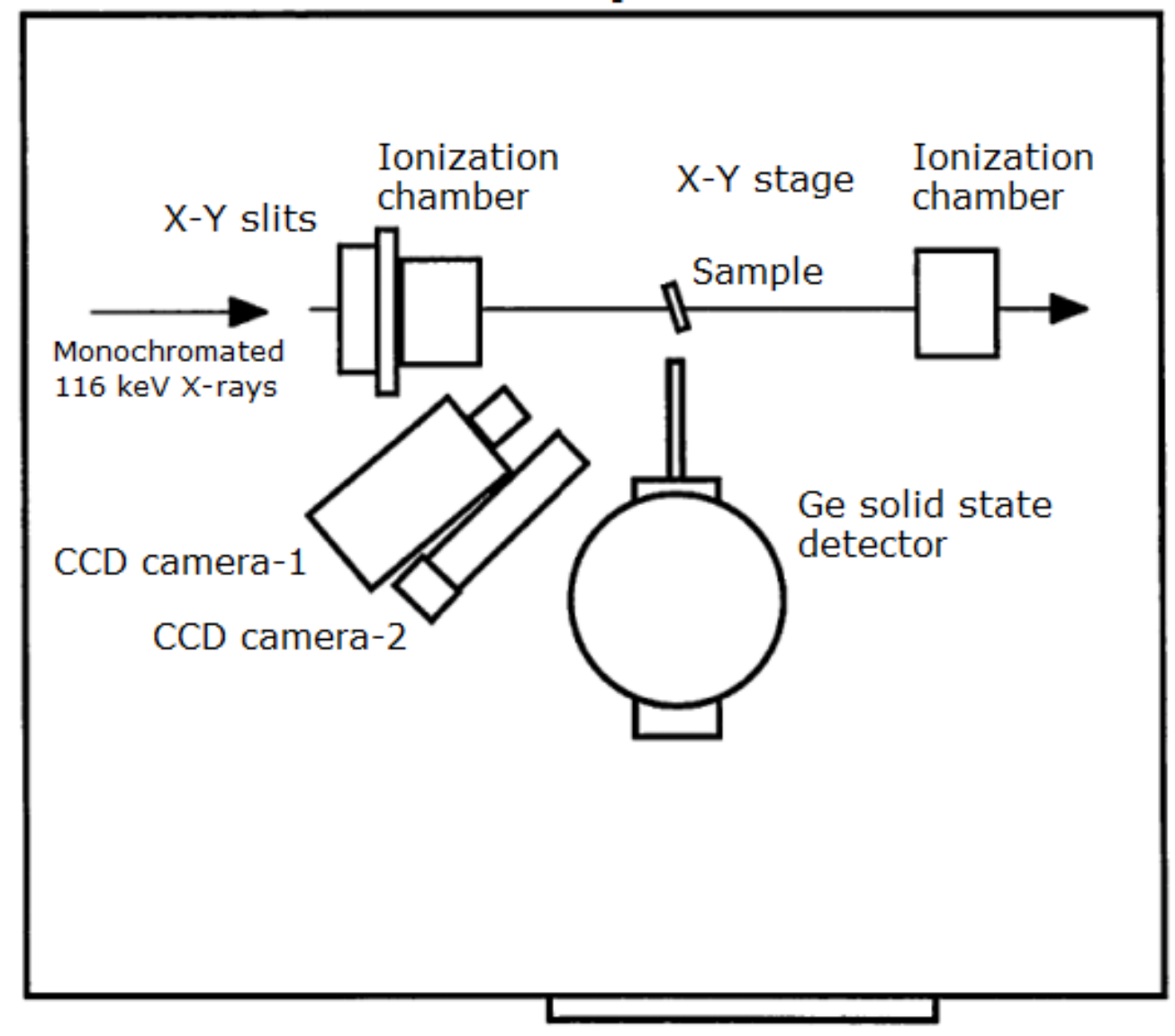

Fig. 5 Schematic diagram of BL-08W at SPring-8 taken from Profs. Taniguchi and Hayakawa's document \#6. 


\section{Experimental station}

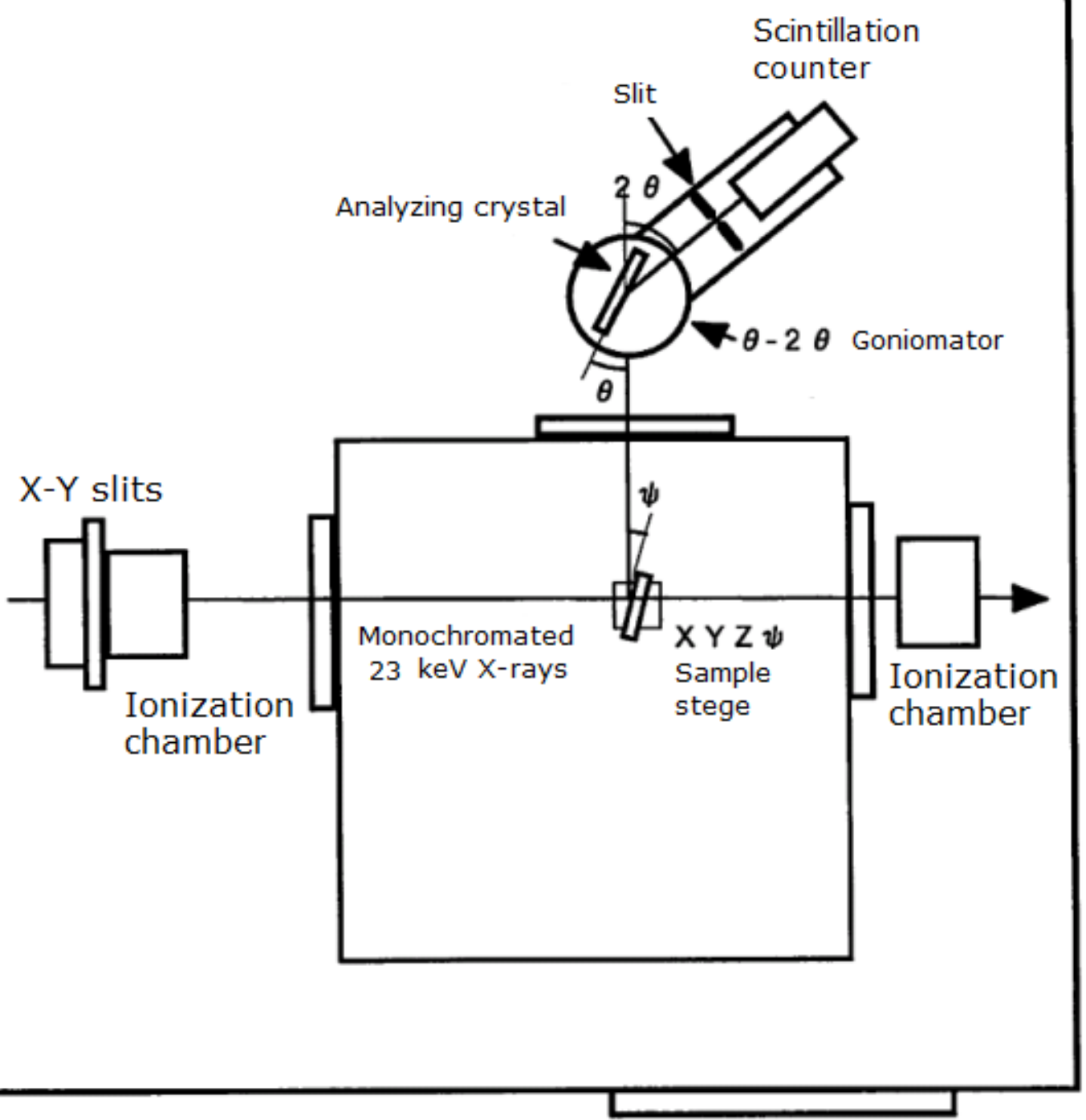

Fig. 6 Schematic diagram of BL-39XU at SPring-8 taken from Document \#6.

Figs. 5 and 6 show schematic illustrations of the experimental stations at BL-08W and BL-39XU, respectively, at SPring-8, which Prof. Taniguchi and Hayakawa used. Incident X-rays of $116 \mathrm{keV}$ were used at BL-08W (Nakai used $115 \mathrm{keV}$ on the same beamline); one spectrum was 1000 seconds or 3000 seconds accumulated by a Ge solid state detector at BL-08W. Beam size was $0.3 \mathrm{~mm} \times 0.5 \mathrm{~mm}$, as is mentioned in the introduction.

$23 \mathrm{keV}$ incident X-rays were used at BL-39XU, with $\mathrm{LiF}(200)$ analyzing crystal for the $\mathrm{WD}-\mathrm{XRF}\left(\mathrm{Mo} \mathrm{K} \alpha_{1}=10.138^{\circ}(\theta), \mathrm{K} \alpha_{2}=10.200^{\circ}\right)$ analysis. $10 \mu \mathrm{m}$ thick Mo foil 
was used as a reference material. The analyzing crystal was fixed and the scintillation counter was rotated by $1 \% 50$ step and totally 21 steps were measured (therefore the slit width in front of the scintillation counter in Fig. 6 was important for the energy resolution); one channel was $90 \mathrm{~s}$ and one or four iteration(s) were measured, or one channel $200 \mathrm{~s}$ and one iteration was measured, depending on the spectral intensity. The beam size at BL-39XU for WD-XRF was $1 \mathrm{~mm} \times 2 \mathrm{~mm}$, and the take-off angle from the sample surface was $10^{\circ}$.

Fig. 7 is shown representative spectra of Specimen 4 (Here we must note again that the specimen numbers used in Document \#6 are not coherent to those used in \#1170, but Specimen 4 was the same between Documents \#1170 and \#4) measured at BL-08W (Fig. 5). Specimen 4 was measured at different 5 points on the specimen. The beam positions are marked by a small circle on the photos of the specimen (top of Fig. 7). Fig. 8 is shown spectra after the curved backgrounds (passing through the 30 points on a spectrum) were subtracted (top) and enlarged (bottom). Though the spectra are similar to those measured by Prof. Nakai (Figs. 1 and 2), the Rayleigh scattering $(116 \mathrm{keV})$ is included in the plotted region, and the counting intensity is indicated in the ordinate. The absolute intensity is slightly different between left and right spectra in Figs. 7 and 8, which means that the stage of the decay of the synchrotron radiation beam or the mass of the irradiated specimen were different. An artificial dip on the high energy side of $\mathrm{As} \mathrm{K} \beta$ at $12.5 \mathrm{keV}$ indicates that the curved background subtraction was not appropriate. Sum peaks of As and $\mathrm{Ba} \mathrm{K} \alpha$ are also found. 


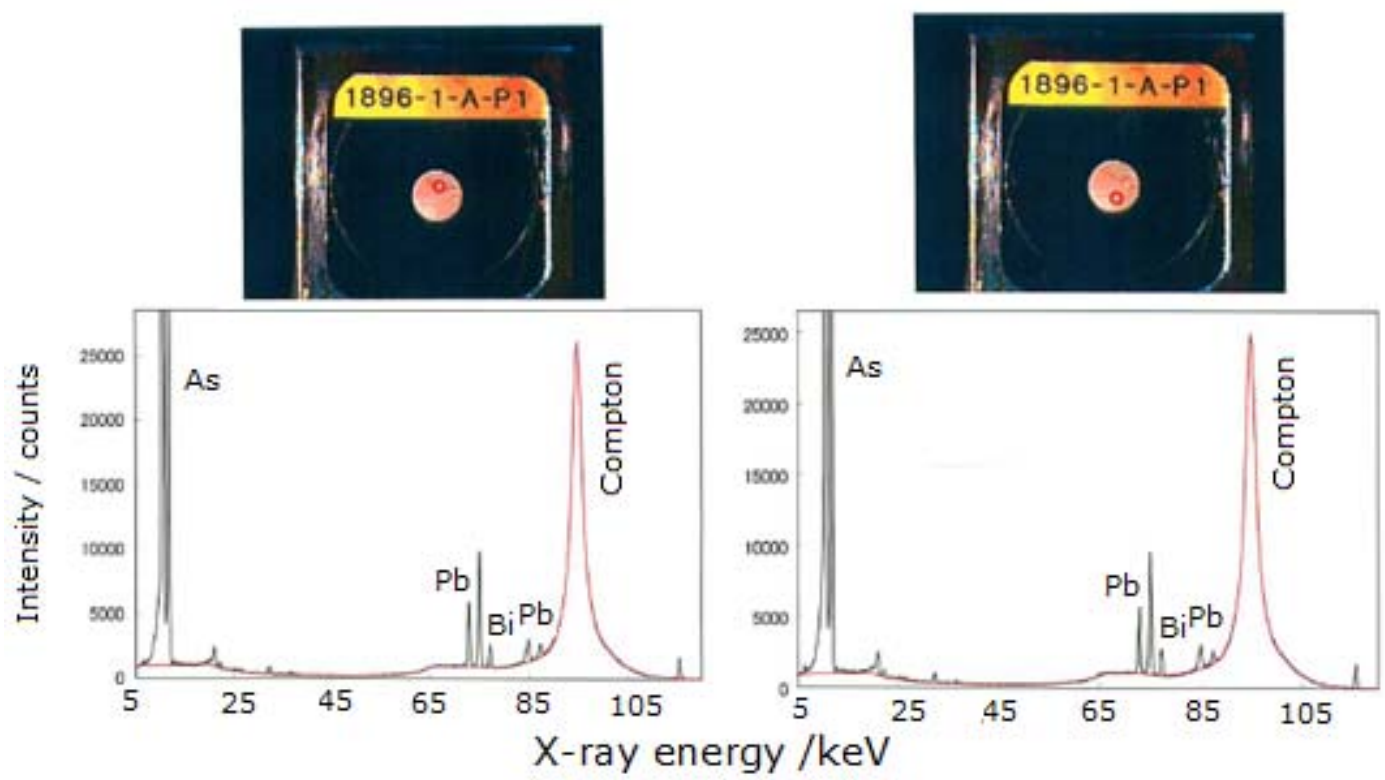

Fig. 7 Photos of Specimen 4 and spectra measured at BL-08W by Profs. Taniguchi and Hayakawa (Document \#6). Spectra at two positions on the same specimen are shown. Beam positions are indicated by small circles on the photo. Totally 5 positions were measured for this specimen. Incident beam was $116 \mathrm{keV}$. Background curve was determined in such a way that 30 points of a measured spectrum were selected and a smooth curve was connected passing through these 30 points. Compton scattering peak is regarded as a background. 


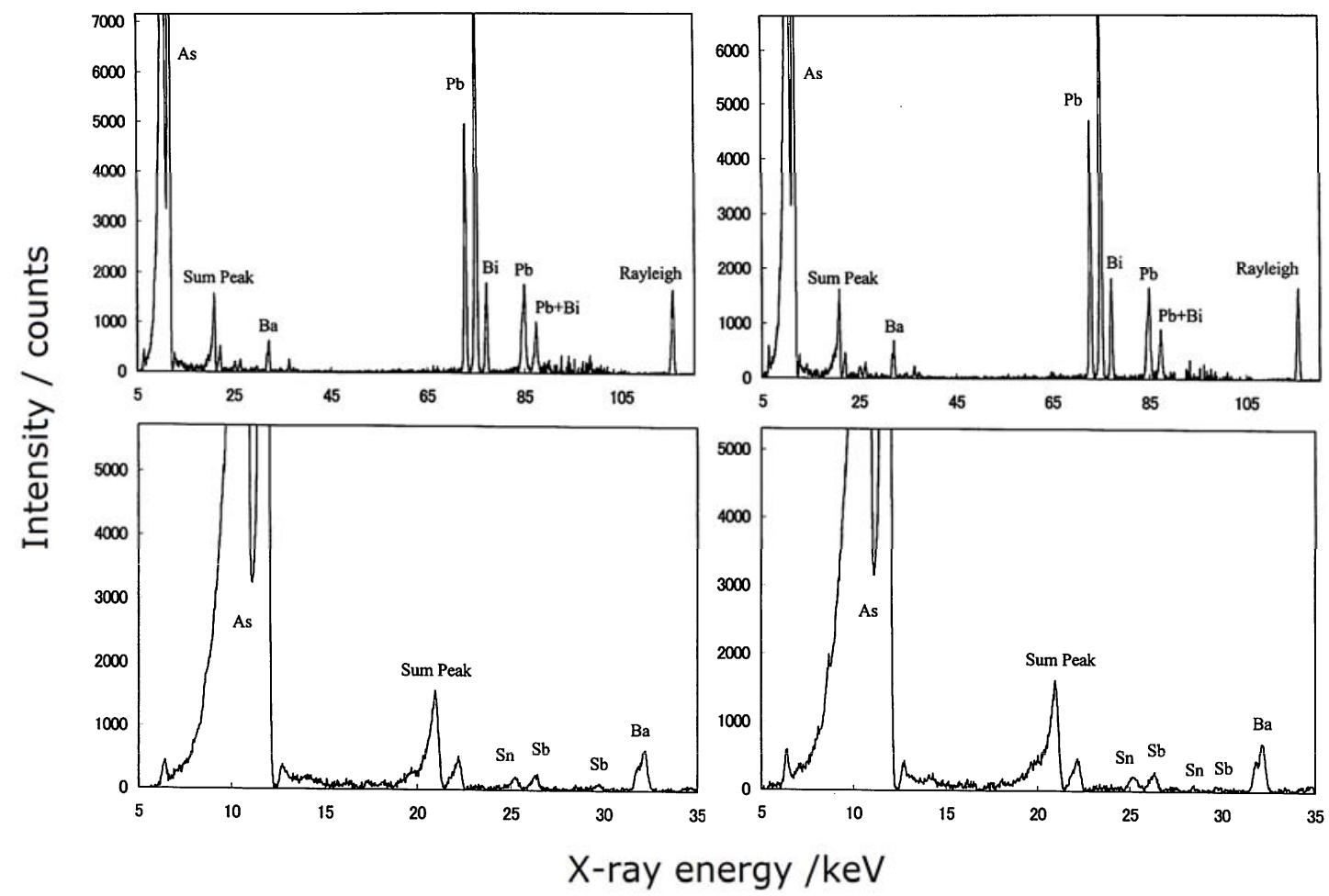

Fig. 8 Top: Spectra of smooth curve background were subtracted from Fig. 7. Bottom: Enlarged spectra of top spectra, taken from \#6.

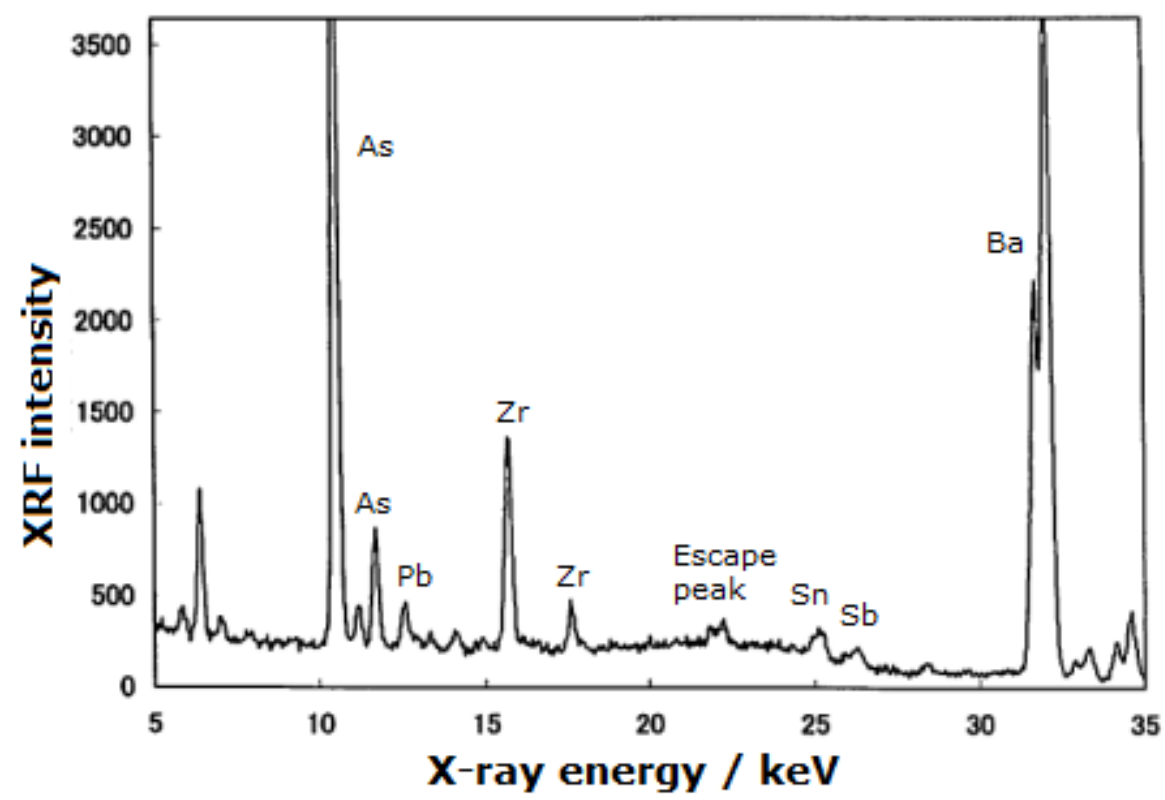

Fig. 9 The enlarged spectrum after a curved background is subtracted for another specimen. 
Another numerically processed spectrum is shown in Fig. 9 reported in Document \#6. In this spectrum, we can find that the absence of the arsenic sum peaks, presence of escape peaks of the stronger $\mathrm{Ba} K \alpha_{1,2}$ peaks. What is more remarkable is that the spectral energy resolution of Fig. 9 is better than those shown in the bottom of Fig. 8. This resolution difference means that the pile up of the X-ray pulses as high as emerging the sum peaks will make worse the energy resolution of the EDX spectra. The $\mathrm{Ba} \mathrm{K} \alpha_{2}$ is separated from $\mathrm{K} \alpha_{1}$ in Fig. 9, whereas those in Fig. 8 are only a low energy shoulder. Due to the better energy resolution, we can say that the spectrum shown in Fig. 9 is spectroscopically better than those shown in Figs. 1 and 2.

Fig. 10 is the plots of X-ray peak intensities as a function of the sample thickness, calculated by Hayakawa (\#6). The Rayleigh scattering was at $116 \mathrm{keV}$, and thus relatively transparent, resulted that at even $500 \mu \mathrm{m}$ thickness, the scattering intensity is still proportional to the thickness of the sample. Bi Ko is also high energy over $75 \mathrm{keV}$, and the behavior is similar to Rayleigh scattering. On the other hand, Sb $\mathrm{K} \alpha$ is relatively low energy ( $26 \mathrm{keV}$ ), and thus $200 \mu \mathrm{m}$ is already opaque and the XRF intensity becomes saturated. Based on these theoretical calculations, Hayakawa described that the $\mathrm{Sn}, \mathrm{Sb}$, and Mo intensities should be normalized with respect to As intensity ( $\mathrm{Sn}, \mathrm{Sb}$, and Mo Ka integral intensities were divided by As intensity), in order to make the calibration curves. On the other hand, $\mathrm{Bi}$ and $\mathrm{Ba}$ are normalized by the Rayleigh scattering intensity. All the normalizations should be done, of course, after a linear background has been subtracted. Hayakawa indicated that the quotient value of the Rayleigh scattering intensity divided by the As XRF intensity is proportional to the sample thickness. Hayakawa plotted the calibration curves of important impurity elements for several As pesticide references against the ICP-AES analysis which has also been performed by him, resulting that some reference pesticides were on a straight line, as a calibration curve, while some were scattered from the straight lines. Hayakawa used specimens collected by the police, of which amount was enough as reference materials to draw the calibration curves between the SR-XRF and ICP-AES. For those reference pesticide samples scattered from the straight lines, Hayakawa performed analysis three times by the ICP-AES, starting from the sample preparation, and concluded that the samples were inhomogeneous. 

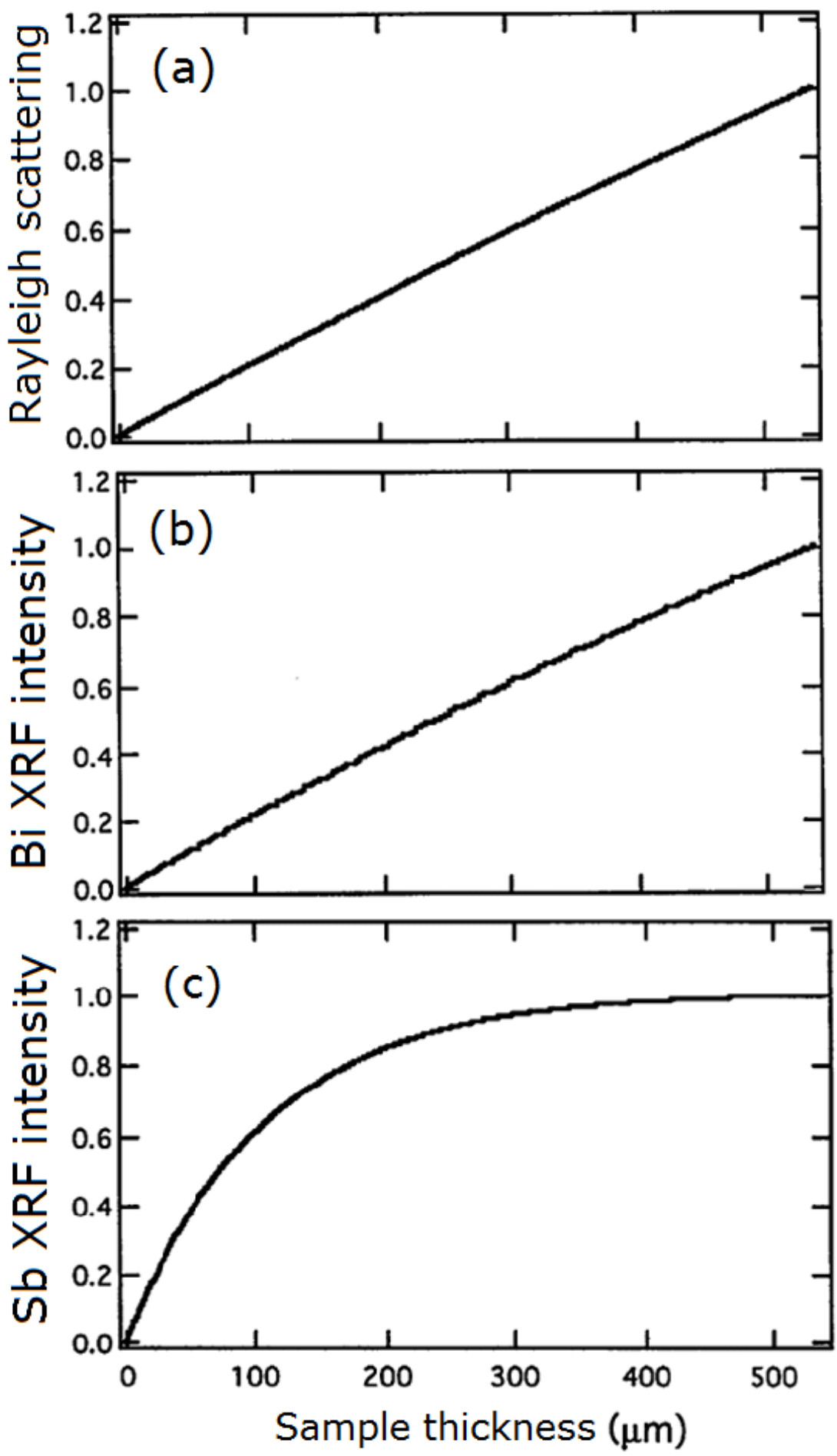

Fig. 10 Sample thickness dependence of (a) $116 \mathrm{keV}$ Rayleigh scattering, (b) Bi Ka (77 $\mathrm{keV}$ ), and (c) Sb Ka (26 keV) XRF peaks, calculated by Prof. Hayakawa, taken from Document \#6. 


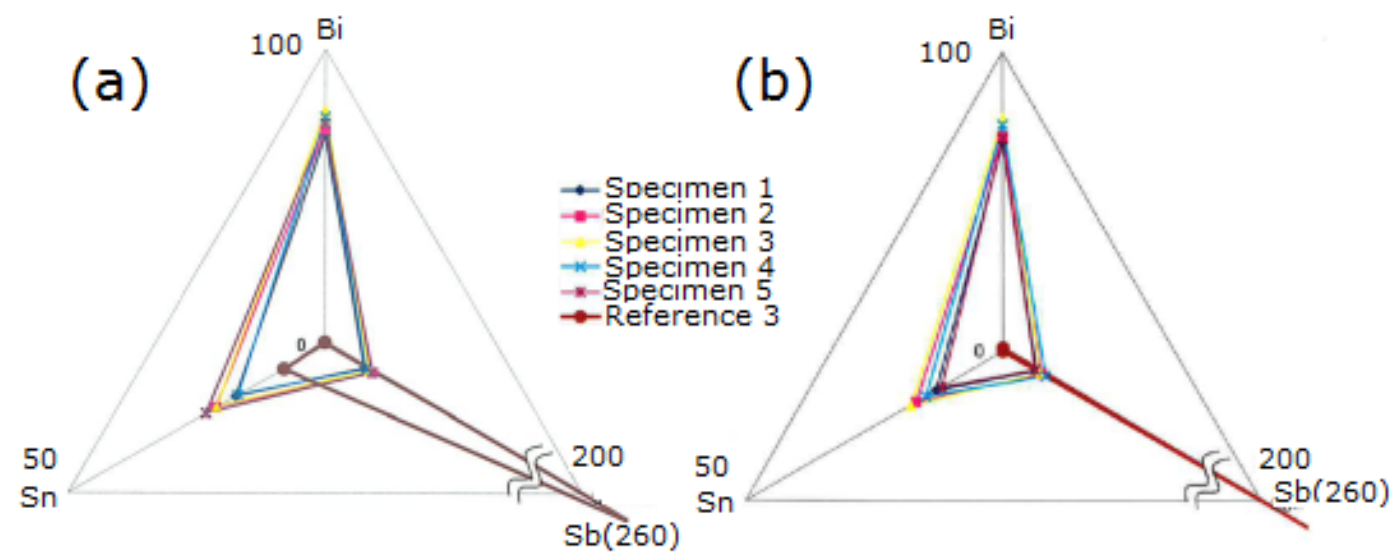

Fig. 11 "Radar chart" of (a) Taniguchi-Hayakawa's Document \#6, estimated from 30-point passing through background subtracted spectra, (b) after Hayakawa's addenda (\#7) and revision (\#8), where linear background was subtracted. Specimens 1-5 are those requested the identification, Referene 3 is a pesticide reference. The concentration profiles are different between Specimens 1-5 and Reference 3. The profiles become more identical after the background subtraction method was improved (b).

Based on the above numerical processes, Taniguchi and Hayakawa plotted the "radar chart" in Document \#6 as shown in Fig. 11(a), where Specimens 1-5 are clearly different from Reference 3, which means that their origins are different, but Specimens 1-5 originated from the same supplier. Fig. 11(b) shows that the conclusion is the same as Fig.11(a) but the reliability becomes better. Tin in Reference 3 was overestimated in Fig. 11(a), because of the inappropriate 30-point curve background used in Document \#6. Fig11(b) used the linear background.

Fig. 12 shows the "radar chart" analyzed by Dr. Marumo et al. in Document \#1168 using ICP-AES just after the summer festival (1998). Table 3 shows quantitative analysis by ICP-AES by Marumo et al. The concentrations of the impurity elements ( $\mathrm{Se}, \mathrm{Sn}, \mathrm{Sb}, \mathrm{Pb}$, and $\mathrm{Bi}$ ) are of the order of a few tens of ppm. The "radar chart" of ICP-AES in Fig.12 is the result of 5 elements, while those of Fig. 11 (SR-XRF) are only 3 elements, even though by using the SPring-8 $3^{\text {rd }}$ generation synchrotron radiation facility. We believed that the $3^{\text {rd }}$ generation SR-XRF analysis was superior to the conventional ICP-AES [1], but this was not true. From the documents submitted to the court, the ICP-AES---a conventional analytical method---was superior to the newest synchrotron facility, in order to identify the 
specimens collected at the criminal scene. Of cause Mo was a new finding of the SR-XRF analysis, but it was too weak as an evidence for the death sentence.

Fig. 13 shows a representative WD-SR-XRF spectrum of Mo K $\alpha_{1,2}$ measured at BL-39XU by Profs. Taniguchi and Hayakawa (\#6). Total channel number is 21 as is described above. Mo $\mathrm{K} \alpha_{1}: \mathrm{K} \alpha_{2}$ intensity ratio is about 2:1. At this point, we can confirm the existence of Mo in the murder-related pesticide specimens.

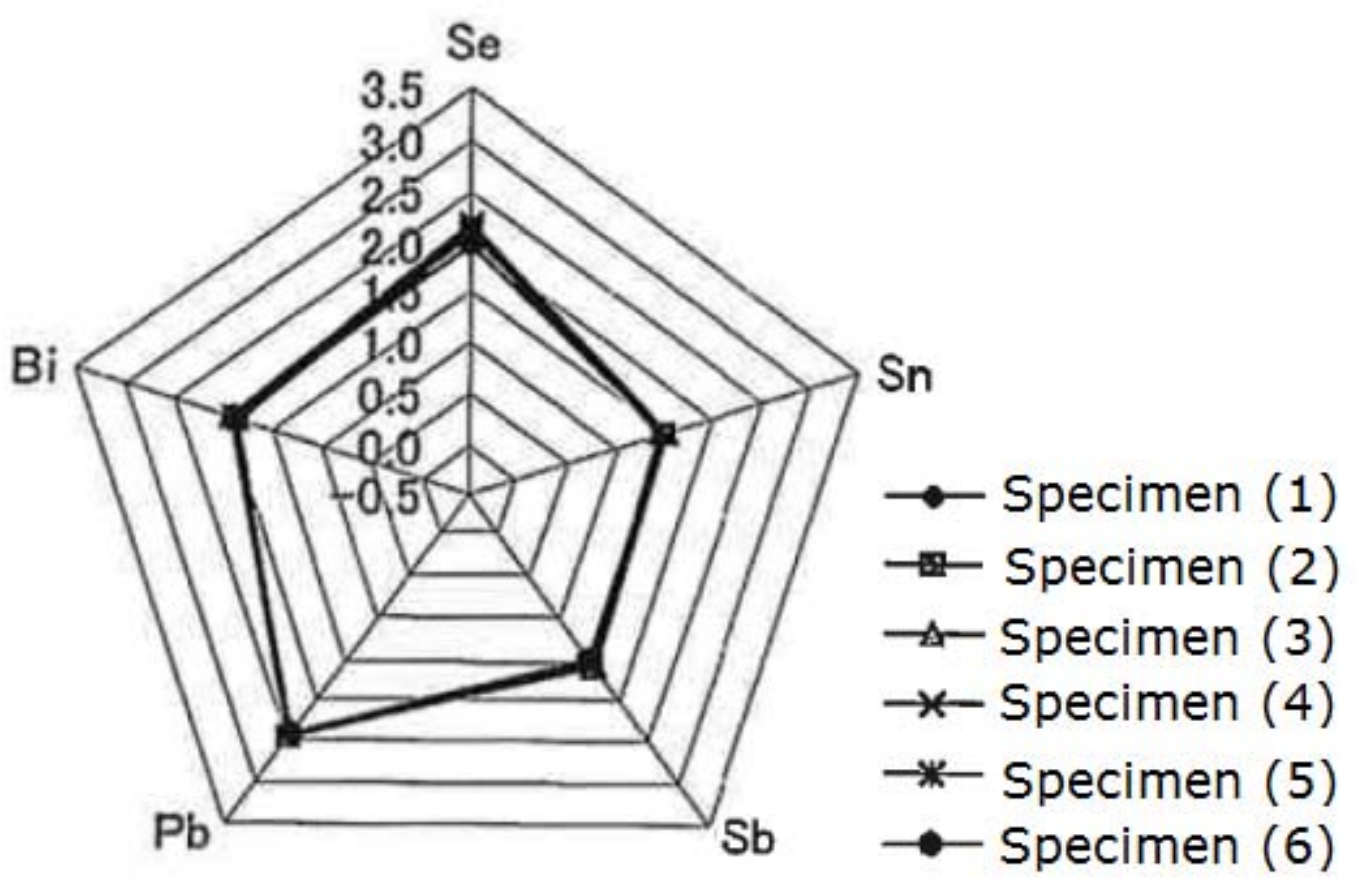

Fig.12 "Radar chart" obtained from ICP-AES analysis by Dr. Marumo et al. (\#1168). We must note here that specimen numbers do not correspond to those shown in Figs. 1 and 11.

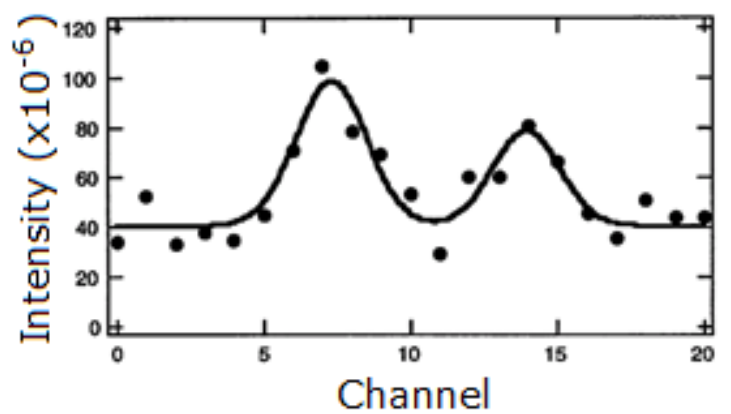

Fig. 13 Mo K $\alpha_{1,2}$ WD-SR-XRF spectrum measured at BL-39XU, SPring-8, taken from 
Document \#6.

Table 3 Concentration of elements analyzed by Dr. Marumo et al. using ICP-AES, taken from Document \#1168. The specimen numbers are changed in such a way that corresponds to Nakai's document. Specimen 6 was not analyzed by Marumo et al.

\begin{tabular}{|c|c|c|c|c|c|c|}
\hline Specimen \# & 1 & 2 & 3 & 4 & 5 & 7 \\
\hline $\mathrm{Na}$ & $35 \mathrm{ppm}$ & $32 \mathrm{ppm}$ & $59 \mathrm{ppm}$ & $70 \mathrm{ppm}$ & $87 \mathrm{ppm}$ & $393 \mathrm{ppm}$ \\
\hline $\mathrm{Mg}$ & 6 & 5 & 105 & 49 & 203 & 16 \\
\hline $\mathrm{Al}$ & 0 & 0 & 308 & 170 & 2266 & 138 \\
\hline $\mathrm{P}$ & 5 & 5 & 85 & 86 & 234 & 7 \\
\hline $\mathrm{Ca}$ & 3 & 6 & 3965 & 147 & $>10000$ & $>10000$ \\
\hline $\mathrm{Cr}$ & 0 & 0 & 2 & 4 & 4 & 12 \\
\hline $\mathrm{Mn}$ & 1 & 1 & 17 & 15 & 7 & 3 \\
\hline $\mathrm{Fe}$ & 36 & 28 & 303 & 861 & 153 & 146 \\
\hline $\mathrm{Ni}$ & 2 & 2 & 2 & 4 & 7 & 7 \\
\hline $\mathrm{Zn}$ & 203 & 201 & 178 & 205 & 124 & 297 \\
\hline $\mathrm{Se}$ & $99 \pm 19$ & $96 \pm 24$ & $104 \pm 13$ & $96 \pm 2$ & $62 \pm 7$ & 111 \\
\hline $\mathrm{Sn}$ & $23 \pm 3$ & $23 \pm 2$ & $24 \pm 6$ & $20 \pm 2$ & $14 \pm 2$ & 25 \\
\hline $\mathrm{Sb}$ & $27 \pm 1$ & $27 \pm 1$ & $28 \pm 1$ & $23 \pm 7$ & $16 \pm 2$ & 23 \\
\hline $\mathrm{Pb}$ & $198 \pm 4$ & $195 \pm \underline{4}$ & $175 \pm \underline{8}$ & $166 \pm 3$ & $124 \pm 5$ & 180 \\
\hline $\mathrm{Bi}$ & $57 \pm 6$ & $55 \pm 3$ & $62 \pm 20$ & $49 \pm \underline{1}$ & $35 \pm 2$ & 55 \\
\hline $\mathrm{As}$ & $77.0+3.4 \%$ & $77.6+4.0 \%$ & $68.6+2.2 \%$ & $65.7+1.6 \%$ & $48.7+0.8 \%$ & $74.8 \%$ \\
\hline
\end{tabular}

4. Recent progress

After submission of the first version of the present review paper in August 2012, some new facts became clear. On November 2 nd, Prof. Nakai gave a talk in an Annual X-ray Discussion Meeting, Japan, where 160 participants gathered, brought forward a counterargument to my Japanese version review [9] published in March 2012. Nakai's talk was on the last day in the X-ray Discussion Meeting in Nagoya, Japan, from October 31 to November 2nd, 2013. In his talk, it was not clear whether Mo was found only in the saleswoman's house and the paper cup, or also other neighborhood houses. I asked this during the question time after his talk. Nakai's reply was surprising to the audience that all the specimens collected at neighborhood houses, the saleswoman's house, curry pot, and paper cup, were all identical, based on the indexed elements of Mo, Sn, Sb, and Bi. 
Therefore the SR-XRF was not a key evidence. This was a new fact opened to the X-ray analysis society, Japan. When I heard this reply that Nakai only use the heavy metals such as $\mathrm{Mo}, \mathrm{Sn}, \mathrm{Sb}$, and $\mathrm{Bi}$ for the origin identification of specimens collected neighborhood houses including the suspect, as well as the paper cup and curry pot, I thought that if other minor lighter elements ( $\mathrm{Na}, \mathrm{Mg}, \mathrm{Al}, \mathrm{Si}, \mathrm{P}, \mathrm{S}, \mathrm{Cl}, \mathrm{K}, \mathrm{Ca}$, and transition metals) were analyzed, then we could identify the murder. Because these light elements reflect how the pesticide was stored in each house. I checked the Nakai's spectra in the low energy region, and found that Fe and $\mathrm{Zn}$ peaks were found (Figs. 14 and 15). Thus I read the net peak intensity of Fe, Zn, Mo, Ba, and As-sum from Figs. 14 and 15, which have been newly plotted from Nakai's Excel raw data, and plotted as shown in Fig. 16. The first order sum peak $(K \alpha+K \alpha)$ intensity is proportional to its parent peak $(K \alpha)$ intensity. Thus we use the As sum peak in Fig. 16.

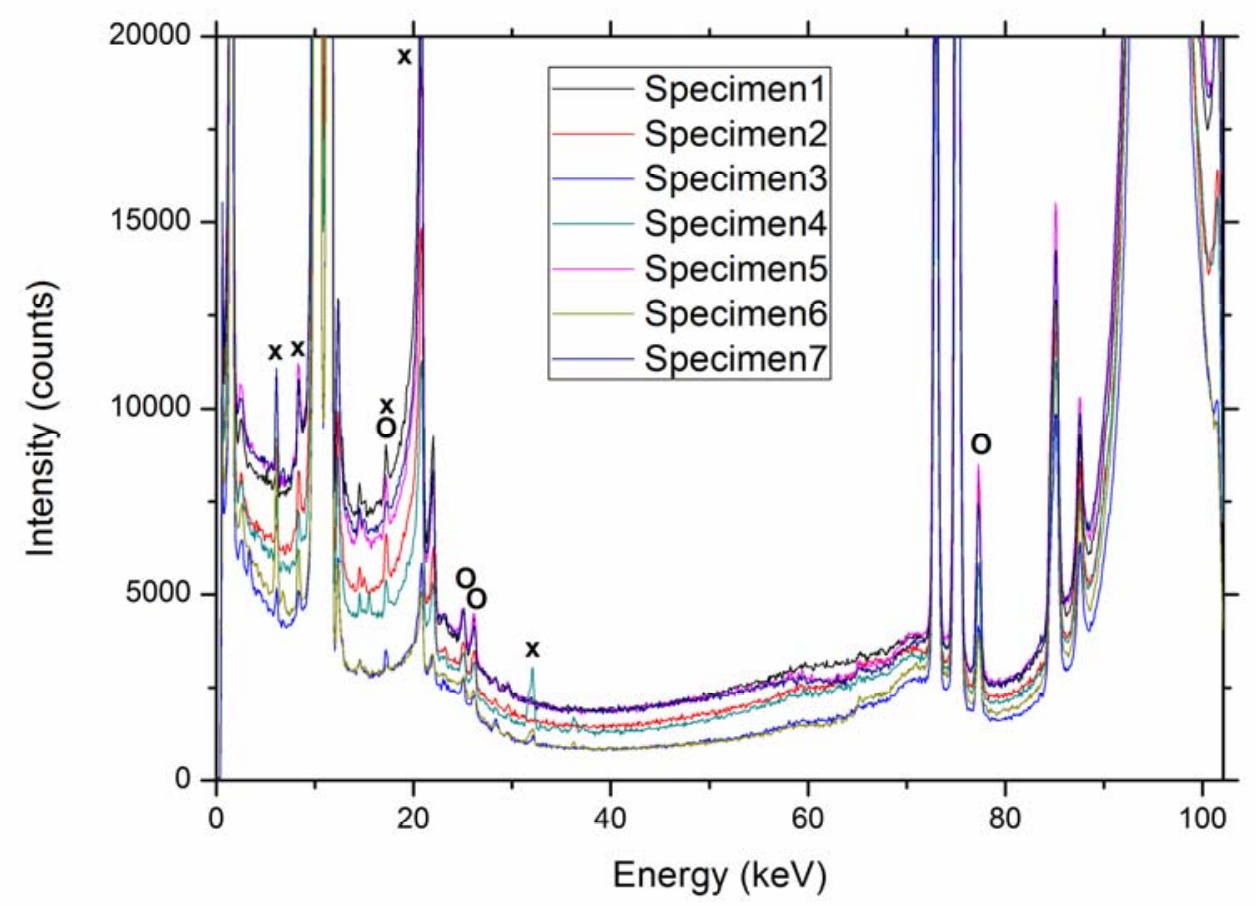

Fig. 14 Replot of Nakai's X-ray spectra for Specimens 1-7. If paper cup (Sepcimen 7) spectrum and the spectrum of arsenic stored in the saleswoman's house (Specimen 6) are same, then the saleswoman should be the murder. Peaks marked by " $O$ " are those used by Nakai, while peaks marked by " $x$ " are peaks used in Ref.[10] (taken from Ref.10 with permission). 


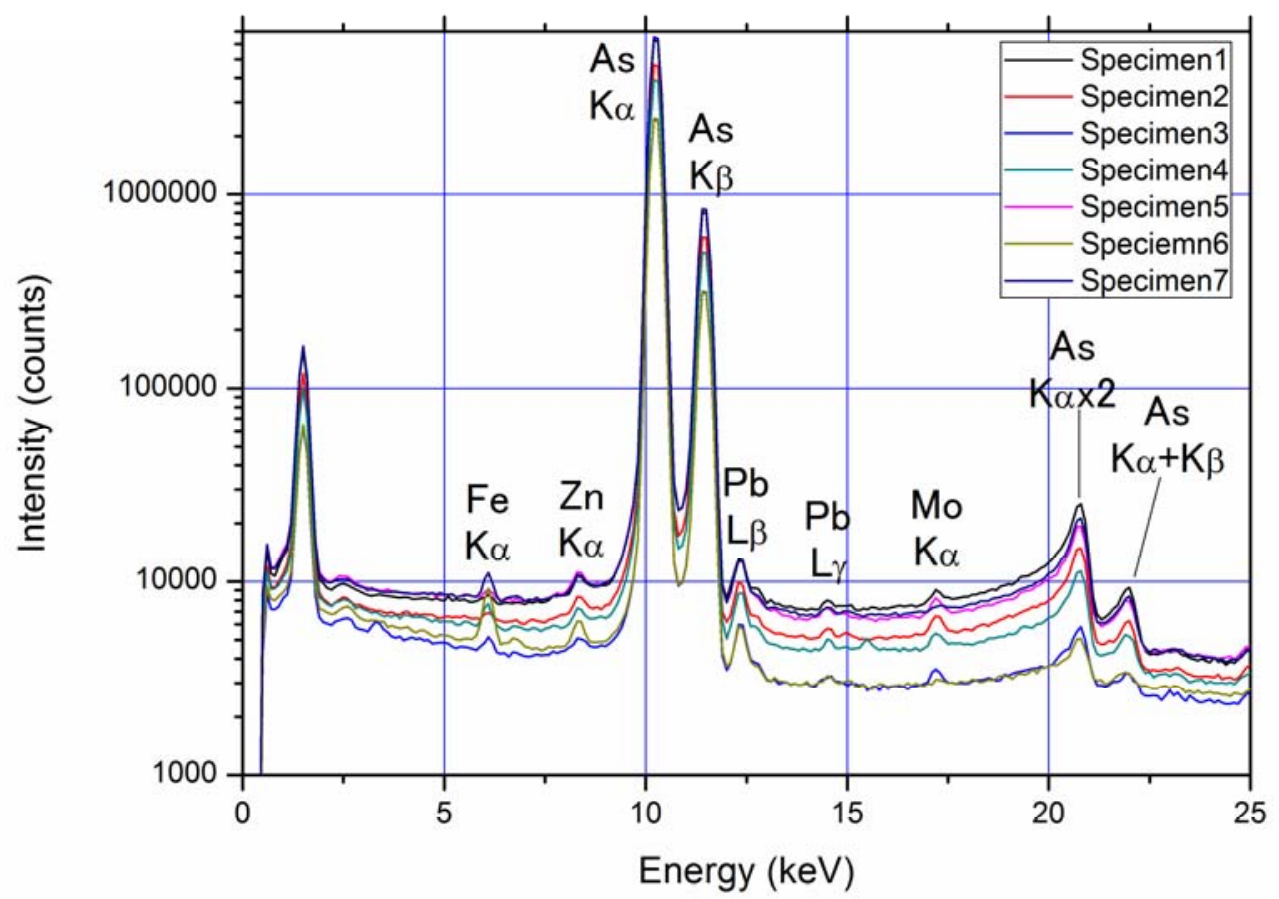

Fig. 15 Log plot of the same spectra shown in Fig. 14. The spectra are from top to bottom as an ordering of Specimens 1, 7, 5, 2, 4, 6, and 3 (taken from Ref.10 with permission).

From Table 3 shows the ICP-AES results performed by Dr. Marumo et al. ( \#1168), where it is found that Fe is ranging from 28 to 861 ppm, Zn from 124 to $297 \mathrm{ppm}$. On the contrary, $\mathrm{Cr}, \mathrm{Mn}$, and $\mathrm{Ni}$ are almost single ppm level. This is the reason that Fe and $\mathrm{Zn} \mathrm{XRF}$ peaks are visible, while other transition metal elements are not appeared in Fig. 15. The tendency of the $\mathrm{Fe} / \mathrm{Zn}$ concentration ratio for Specimens 1, 2, and 4 are well reproduced in the XRF peak intensity in Fig. 16. The XRF sensitivity is quite similar between Fe and Zn for $115 \mathrm{keV}$ X-ray excitation. The Fe/Zn concentration for Specimens 3, 5, and 7 are inverted between Table 3 and Fig. 16. Marumo et al. only analyzed the acid soluble part of the specimens by ICP-AES, but XRF is the total analysis. This may be a source of discrepancy between Table 3 and Fig. 16. However, if we compare Specimen 6 (arsenic found at saleswoman's kitchen) with Specimen 7 (samples from the paper cup), the intensity ratios of Fe: $\mathrm{Zn}:$ As are significantly different each other. 


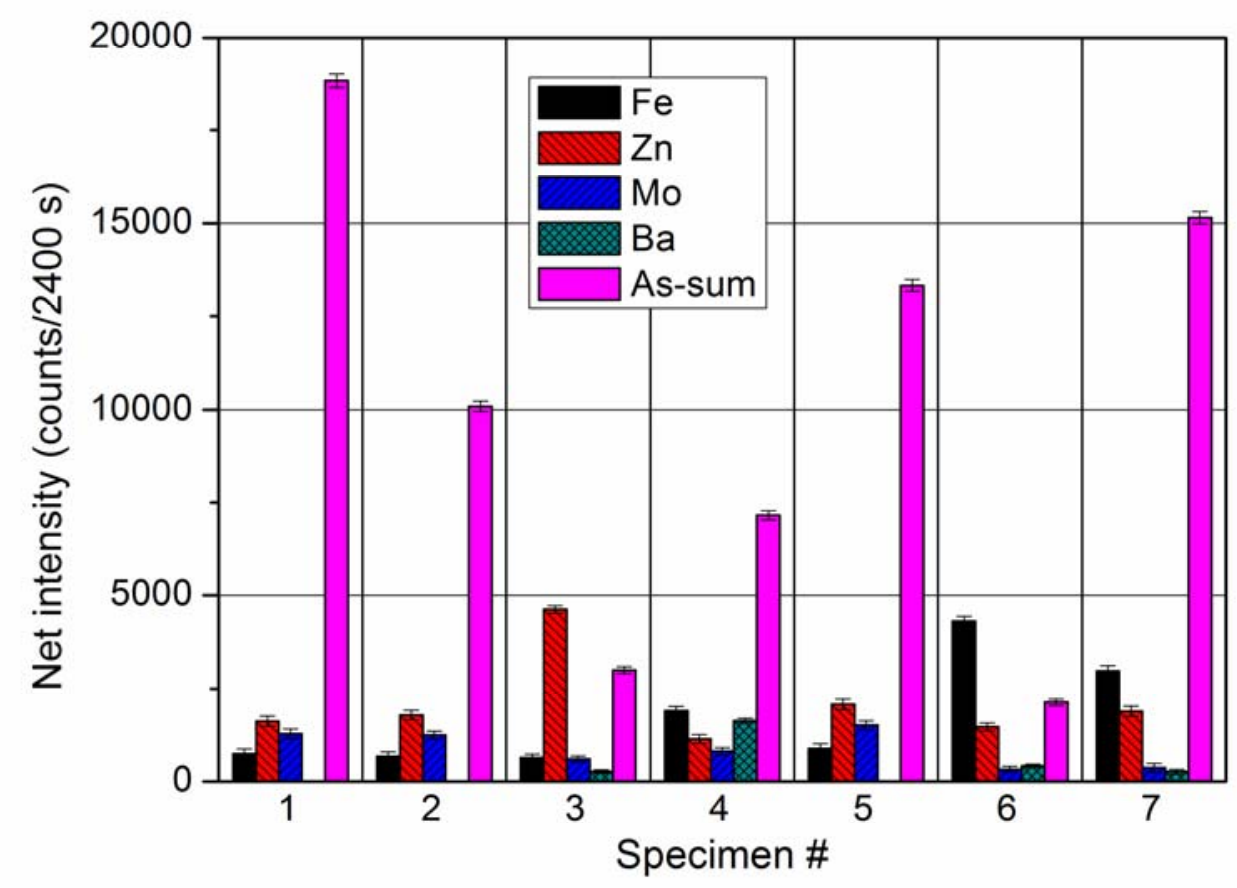

Fig. 16 Net intensity of $\mathrm{Fe}, \mathrm{Zn}, \mathrm{Mo}, \mathrm{Ba}$, and As-sum peaks. Specimens 1-5 were collected at neighborhood houses, Specimen 6 was found at the suspected saleswoman's kitchen, and Specimen 7 from paper cup (taken from Ref.10 with permission).

\section{Concluding remarks}

Gohshi and I [1] wrote in the guest editorial of the Japan special issue of the journal, X-Ray Spectrometry, published in 1999: "We estimate that the minimum detection limit of SR-XRF as performed by Professor Nakai was better than that of ICP-MS", also we proudly wrote, "The key evidence for the arrest was XRF analysis." After I read many documents submitted to the court, I became to know that the SR-XRF analysis was not possible unless the results of ICP-AES was known (otherwise even the beamline selection was not possible), and the concentration analyzed was more than a few tens of ppm ( $\mathrm{Sn}, \mathrm{Sb}$ and Bi in Table 3), and can now be analyzed even by a handheld $\mathrm{XRF}$ spectrometer, if the total amount of the sample is a few grams. This is the case for most of the specimens corrected at the neighbors. Only the exceptions were the "paper cup" and arsenic found in the saleswoman's kitchen, and SR-XRF may be necessary for these specimens. Mass spectrometry may be an alternative to SR-XRF analysis.

Prof. Nakai's analysis was SR-XRF and the identification was based on the 
"pattern recognition". On the other hand, Profs. Taniguchi and Hayakawa subtracted the background, normalized by the Rayleigh scattering (for thin transparent target) or As $\mathrm{K} \alpha$ (for thick opaque target). This kind of normalization is important, because the sample thickness is not the same for all the specimens, and the SR beam decays exponentially after the injection of the electrons into the storage ring. Hayakawa successfully performed these data processings, and obtained the quantitative elemental concentrations of the interested elements, with the reliability of the analysis.

Synchrotron XRF analysis has always been complicated analytical method and very difficult to understand, especially for lawyers. During discussions in the court, it was misunderstood that the Taniguchi-Hayakawa's quantitative XRF analysis was something artificial and Nakai's raw data was concluded to be better than Taniguchi-Hayakawa's processed data, and the final judge, death sentence, was based on Nakai's "pattern recognition". However the method used in the Taniguchi-Hayakawa document was the first report of quantitative analysis of high energy SR-XRF analysis, and Hayakawa's addenda and revision are more reliable than Nakai's data, at least from the X-ray analysis expert's view. The ICP-AES used 29.1 $\mathrm{mg}$ of a key specimen, and this was regarded as wasted consumption of the important specimen. Nakai said that the amount of the pesticide specimen found in the saleswoman's kitchen which could be used for SR-XRF analysis was less than $0.1 \mathrm{mg}$. Though Nakai et al. [11] published scientific paper of high energy XRF spectrometry, neither blank spectrum nor the elastic scattering peak were shown.

Arsenic analysis of Napoleon I has been reviewed by Ref.[2], where neutron activation analysis was used, and recently performed by Chevallier et al. [12] and Carvalho et al. [13] using the SR-XRF analysis. From these reports, arsenic analysis of hair is very problematic because of surface effects or contamination. As Papp et al. [14] reported, the low energy response function of a solid state detector has many problems. A part of the response function problem has been discussed at the comparison of Figs. 8 and 9, where absence of the sum peak is an important factor for a good energy resolution of the measured spectra. This point is misunderstood in the court as is mentioned in the introduction. The beam size and pile up are trade-offs. If the beam size is large, and therefore the incident X-ray is strong, the pile up takes place and thus the sum peaks become stronger, and consequently the response function of a detector becomes worse. We can observe an average composition of a wide area specimen of an inhomogeneous specimen and at the same time we can observe minor impurity elements with a strong and wide X-ray beam. On the other hand, when the beam size is small, in order to obtain the average composition, scanning the beam on the 
specimen is needed, but we can avoid the saturation of the X-ray detector. It is difficult to say which one (small or wide beam size) is better. However it can be said that when the sum peak appears, we must be very careful for the spectral interpretation. Though it is widely believed that SR-XRF is an extremely sensitive elemental analysis method, sometimes SEM-EDX is more sensitive than SR-XRF for soft X-rays or light elements, as is compared by Kawai et al.[14] introducing an SEM-EDX into a SPring-8 beamline.

The first version of the present review has been published on March 2012 in Japanese (submission was November 2011) [9], which reviews all kinds of X-ray analysis methods in the documents submitted to the court, such as SEM-EDX, XRF, transmission X-ray imaging, SR-XRF, and XRD. The present review is revised but focusing on the SR-XRF analysis. The prosecutor's document has been added in the present review. I become to know from the procecutor's document, that the conclusion in the court was inverse to that of the X-ray specialists. This point is also included in the present review, and several revisions have been made in the present review from the Japanese version, after the publication of the Japanese version.

Thanks are due to those who gave me comments on the Japanese version, such as SII SAE 5120 uses Mo tube. Thanks are also due to Prof. Yohichi Gohshi for his nomination of the present author during the editorial board meeting at Wien on the occasion of European Conference on X-Ray Spectrometry (EXRS) June, 2012, as a potential author for the forensic special issue of the journal, X-Ray Spectrometry, because he read the Japanese version [9]. Thanks are also due to Dr. Melanie Bailey, University of Surrey, for waiting my manuscript.

\section{References}

[1] J. Kawai, Y. Gohshi. X-Ray Spectrom. 1999, 28, 419.

[2] R. H. Goldsmith. "More Chemistry and Crime - From Marsh Arsenic Test to DNA Profile”, Eds. S. M. Gerber, R. Saferstein, American Chemical Society, Washington DC, 1977, Chapt. 8, p.149.

[3] I. Nakai. Legal advice document "Prosecution \#1170", February 19"h, 1999.

[4] K. Taniguchi, S. Hayakawa. Legal advice document “Court Order \#6”, November $5^{\text {th }}$, 2002.

[5] K. Taniguchi, S. Hayakawa. Legal advice document “Court Order \#7", November $15^{\text {th }}$, 2002.

[6] K. Taniguchi, S. Hayakawa. Legal advice document "Court Order \#8", November $22^{\text {nd }}, 2002$.

[7] Y. Marumo, S. Suzuki, H. Ohta. Legal advice document "Prosecution \#1168", 
December 15 1999.

[8] A. Fukuda. Prosecutor's reply to the accused person's request of additional chemical anaysis, March 23 2012.

[9] J. Kawai. Adv. X-Ray Chem. Anal. Japan, 2012, 43, 49.

[10] J. Kawai. Adv. X-Ray Chem. Anal. Japan, 2013, 44, 169.

[11] I. Nakai, Y. Terada, M. Itou, Y. Sakurai. J. Synchrotron Rad. 2001, 8, 1078.

[12] P. Chevallier, I. Ricordel, G. Meyer. X-Ray Spectrom. 2006, 35, 125.

[13] M. L. Carvalho, A. F. Marques, J. Brito. AIP Conf. Proc. 2003, 653, 522.

[14] T. Papp, A. T. Papp, J. A. Maxwell. Anal. Sci. 2005, 21, 737. (http://www.jstage.jst.go.jp/article/analsci/21/7/737/_pdf)

[14] J. Kawai, H. Ishii, Y. Matsui, Y. Terada, T. Tanabe, I. Uchiyama. Spectrochim. Acta Part B, 2007, 62, 677. 